\title{
Erratum
}

\section{Minerals of the rhabdophane group and the alunite supergroup in microgranite: products of low-temperature alteration in a highly acidic environment from the Velence Hills, Hungary - ERRATUM}

\author{
Martin Ondrejka, Peter Bačík, Tomáš Sobocký, Pavel Uher, Radek Škoda, Tomáš Mikuš, Jarmila Luptáková \\ and Patrik Konečný \\ doi.org/10.1180/mgm.2018.137, Published by Cambridge University Press, 02 July 2018.
}

An error was introduced in the final editing stages of production of this paper in Mineralogical Magazine, 82(6), 1277-1300 under the headings Discussion, subheading: ASM and RGM compositional variations, p 1296; the word "should" was replaced mistakenly by "shouldn't"

The correct text is:

"All these data together with Fe-rich RGM from the Velence Hills suggest that the incorporation of $\mathrm{Fe}^{2+}$ and $\mathrm{Fe}^{3+}$ in the RGM is possibly via above-mentioned substitution mechanisms but does not produce a valid end-member and should be included in formula calculation."

\section{Reference}

Martin Ondrejka, Peter Bačík, Tomáš Sobocký, Pavel Uher, Radek Škoda, Tomáš Mikuš, Jarmila Luptáková and Patrik Konečný. (2018) Minerals of the rhabdophane group and the alunite supergroup in microgranite: products of low-temperature alteration in a highly acidic environment from the Velence Hills, Hungary. Mineralogical Magazine, Published by Cambridge University Press, 02 July 2018. doi.org/10.1180/mgm.2018.137 